\title{
Relationship Between Expression of $\beta 3$-Adrenoceptor mRNA in Bladder Mucosa and Urodynamic Findings in Men with Lower Urinary Tract Symptoms
}

\author{
Yoshiki Kurizaki, ${ }^{1}$ Osamu Ishizuka, ${ }^{1}$ Tetsuya Imamura, ${ }^{1}$ Osamu Nishizawa, ${ }^{1}$ \\ and Karl-Erik Andersson ${ }^{2}$
${ }^{1}$ Department of Urology, Shinshu University School of Medicine, Matsumoto, Japan
${ }^{2}$ Wake Forest Institute for Regenerative Medicine, Wake Forest University School of Medicine, Winston Salem, NC, USA

Correspondence: Osamu Ishizuka M.D., Ph.D.

Department of Urology

Shinshu University School of Medicine

3-1-1 Asahi, Matsumoto, JAPAN 390-8621

Tel.: +81263372661
Fax: +81 263373082
e-mail: ishizuk@ shinshu-u.ac.jp

Running head: $\beta 3$-AR mRNA in Bladder Mucosa and Urodynamic Findings 


\section{Abstract}

Aims: To investigate the relationship between urinary bladder mucosal expression of $\beta 3$-adrenoceptor (AR) mRNA and urodynamic findings in patients with lower urinary tract symptoms and benign prostatic obstruction (BPO). Methods: During surgical prostate resection of 32 BPO patients, mucosal biopsies were collected and analyzed by reverse transcriptase polymerase chain reaction to determine the expression level of $\beta 3-\mathrm{AR}$ mRNA. First desire to void (FDV) and strong desire to void (SDV), detrusor overactivity (DO), and bladder outlet obstruction (BOO) were measured preoperatively. Patients with FDVs $<200 \mathrm{ml}$ or SDVs $<300 \mathrm{ml}$ were assigned to the small capacity group $(\mathrm{n}=19)$. Patients with FDVs $>201 \mathrm{ml}$ and SDVs $>301$ $\mathrm{ml}$ were assigned to the large capacity group $(\mathrm{n}=13)$. The same patients with positive DO were also assigned to the DO+ group $(n=11)$, and those with negative DO were assigned to the DO- group $(n=21)$. Finally, patients whose position on the Schäfer nomogram was greater than degree V were assigned to the severe BOO group $(\mathrm{n}=17)$, while those with less than degree IV were assigned to the mild BOO group $(n=15)$. Results: The expression level of $\beta 3$ AR mRNA was similar in both bladder capacity groups and both DO groups. However, the expression level in the severe BOO group was significantly less than in the mild BOO group ( $\mathrm{p}=0.043$ ). Conclusions: The expression of bladder mucosal $\beta 3$-AR mRNA was significantly decreased in patients with severe $\mathrm{BOO}$, suggesting that $\beta 3$-ARs might be affected by the degree of $\mathrm{BOO}$. 


\section{Key words}

$\beta 3$-adrenoceptor, benign prostatic hyperplasia, bladder urothelium 


\section{INTRODUCTION}

By sympathetic stimulation of $\beta 3$-adrenoceptors (ARs) in the urinary bladder wall, urine can be stored under low pressure. Recently, bladder $\beta 3$ ARs have become a therapeutic target for storage symptom issues. For example, a $\beta 3$-AR selective agonist is effective for patients with symptoms such as urinary frequency, incontinence, and urgency. ${ }^{1}$ In animal models with bladder outlet obstruction (BOO), there are few reports regarding the expression level of $\beta 3-\mathrm{AR}$ mRNA in the bladder. Barendrecht et al., using quantitative real time PCR, reported that $\beta 3$-AR mRNA was not up-regulated in rats 7 days after BOO. ${ }^{2}$ However, Park et al., also using quantitative real time PCR, and Western blot, demonstrated an increase in $\beta 3$-AR mRNA expression in rats with $\mathrm{BOO}$ for 8 weeks, although the increase was not statistically significant. ${ }^{3}$ In none of these studies, the mucosa and the detrusor muscle were analyzed separately. To the best of our knowledge, there are no reports that correlate the expression of $\beta 3$-AR mRNA in the human bladder mucosa to urodynamic findings, especially in patients with lower urinary tract symptoms (LUTS) and benign prostatic obstruction (BPO). Thus, in this report we determined the bladder mucosal expression level of $\beta 3$-AR mRNA in LUTS and BPO patients and correlated it with urodynamic parameters such as bladder capacity, detrusor overactivity (DO), and the degree of BOO. 


\section{METHODS}

\section{Patients}

This study was performed with the approval of the Ethics Committee of School of Medicine, Shinshu University, and written informed consent was obtained from all patients. All patients were treated in accordance with the Declaration of Helsinki. None of the patients had any other significant health issues that required recent surgery or use of drugs that could affect the outcomes of this study.

Thirty-two patients with a diagnosis of BPO and who were scheduled for transurethral prostatectomy (TURP, $n=26$ ) or retropubic prostatectomy ( $\mathrm{n}$ =6) at Shinshu University Hospital from October 2006 to October 2010 were enrolled in this study. Prostate specific antigen (PSA) was measured preoperatively, and a prostatic needle biopsy was performed for the patients whose PSA values were more than $4.0 \mathrm{ng} / \mathrm{ml}$. We did not perform biopsies in cases where the PSA elevation was thought to be due solely to prostate enlargement. Prostate volume was measured by ultrasonography.

The pre-operative international prostate symptom score (IPSS) and overactive bladder symptom score (OABSS) were recorded for each patient. The IPSS is composed of the sum score of seven symptoms: feeling of incomplete bladder emptying, frequency, intermittency, urgency, weak stream, straining, and nocturia. The IPSS is used for evaluating LUTS due to benign prostate hyperplasia (BPH). The OABSS is a composite based upon the sum 
score of four symptoms: daytime frequency, nighttime frequency, urgency, and urgency incontinence. ${ }^{4}$

\section{Real-time reverse transcription polymerase chain reaction (RT-PCR)}

Tissue specimens were obtained from the mucosa of the posterior bladder wall during TURP or retropubic prostatectomy by means of transurethral or direct cold punch biopsy. The specimens were immediately put into the RNAlater (150 mg tissue/1.5 ml RNAlater Tissue Protect Tube; QIAGEN Inc., Valencia, CA, USA) and preserved at $-20^{\circ} \mathrm{C}$.

$\beta_{3}$-AR mRNA was quantified by real-time RT-PCR (Bio-Rad Laboratories, Inc., Tokyo, Japan). Expression levels were determined using the ddCt value. Total RNA was extracted from the biopsied mucosa with the RNeasy Mini Kit (QIAGEN Inc.). Concentration of the total RNA was estimated by photometer (Naka Instruments, Co. Ltd., Hitachinaka, Japan). Complementary DNA (cDNA) was synthesized from $0.2 \mu \mathrm{g}$ of the total RNA with the HighCapacity cDNA Archive Kit (Applied Biosystems, Foster City, CA, USA). Real time RT-PCR of the cDNA was performed at $50^{\circ} \mathrm{C}$ for 2 minutes followed by $95^{\circ} \mathrm{C}$ for 10 minutes. These were followed by 40 cycles at $95^{\circ} \mathrm{C}$ for 15 seconds and $60^{\circ} \mathrm{C}$ for 1 minute. The following primer (Applied Biosystems) was used: ADRB3 (Rn00565393_m1) for $\beta_{3}$-AR. Gene activity was expressed as the ratio to the internal standard eukaryotic ribosomal $18 \mathrm{~S}$ ribosomal RNA (Applied Biosystems, Accession Number: X03205). The analysis was done in duplicate for each sample. 


\section{Video urodynamic study}

A pre-operative video urodynamic study was performed for all patients. The study consisted of fluoroscopic monitoring of filling and voiding cystometry with synchronous sphincter electromyography (EMG) through a surface electrode placed on the perineum. A 14fr transurethral catheter (SAFEED Nelaton Catheter® TERUMO Co., Ltd., Tokyo, Japan) and a 4.7fr transurethral catheter (Dretler Urodynamic PFS Catheter®, Cook Urological, Inc., Spencer, IN, USA) were used for bladder filling and intravesical pressure recordings. Contrast medium (room-temperature, 30\% meglumine iotalamate, Conray® Daiichi Pharmaceutical Co., Ltd., Tokyo, Japan) was instilled at a rate of $30 \mathrm{ml} / \mathrm{min}$.

Among the cystometric variables that we recorded were the first desire to void (FDV) and the strong desire to void (SDV), which were defined by the International Continence Society. ${ }^{5}$ The volumes for FDV and SDV were recorded simultaneously with EMG activity using a computer-assisted urodynamic apparatus (Urovision®, Life-Tec Inc., Stafford, TX, USA). All examinations were carried out without any anesthesia or sedatives with the patients lying supine. According to criteria established by Wyndaele, ${ }^{6,7}$ we assigned patients with FDVs $<200 \mathrm{ml}$ or SDVs $<300 \mathrm{ml}$ to the small capacity group (SC group, $\mathrm{n}=19$ ). Patients with FDVs $>201 \mathrm{ml}$ and SDVs $>301 \mathrm{ml}$ were assigned to the large capacity group (LC group, $n=13$ ). The same patients with positive DO were also assigned to the DO+ group $(n=11)$, and those with negative DO were assigned to the DO- group $(n=21)$. Finally, patients whose position on the Schäfer nomogram was greater than degree V 
were assigned to the severe BOO group $(n=17)$, while those with less than degree IV were assigned to the mild BOO group $(n=15)$.

\section{Statistical analysis}

All values were calculated as means \pm standard error of means.

Comparisons were made by Mann-Whitney $U$ test. P-values less than 0.05 were considered statistically significant. 


\section{RESULTS}

All patients were diagnosed with benign prostatic hyperplasia. There were no significant differences in age, PSA, resected mass, pre-operative IPSS, or pre-operative OABSS between the paired groups SC vs. LC, DO+ vs. DO-, and severe BOO vs. mild BOO ( $\mathrm{p}>0.05$ for each comparison, Table I ). The FDV for the SC group was $140.64 \pm 11.09 \mathrm{ml}$, which was significantly less than that of the LC group, $265.50 \pm 25.00 \mathrm{ml}(\mathrm{p}<0.001)$. Similarly, the SDV for the SC group, $220.21 \pm 16.06 \mathrm{ml}$, was also significantly less than that of the LC group, $382.94 \pm 20.43 \mathrm{ml}(\mathrm{p}<0.001)$.

For $\beta 3$-AR mRNA expression levels (ddCt), there were no significant differences in comparisons of SC vs. LC or DO+ vs. DO- groups (Fig. 1). However, patients with severe BOO expressed slightly, but significantly, lower levels of $\beta 3$-AR mRNA than did those with mild BOO $(p=0.043$, Fig. $1)$. 


\section{DISCUSSION}

The $\beta 3-\mathrm{AR}^{8}$ is the predominant $\beta-\mathrm{AR}$ in the human bladder ${ }^{9-11}$, and has recently become a therapeutic target for bladder storage symptoms. ${ }^{12,13}$ However, the site(s) of action and mechanisms involved have not been established. There are several structures in the bladder that could be responsive to $\beta 3$-AR agents, including the detrusor smooth muscle, detrusor vasculature, afferent and efferent nerve terminals, intramural ganglia, urothelium, and interstitial cells. ${ }^{14}$

Nomiya et al. ${ }^{15}$ reported that $97 \%$ of $\beta$-AR mRNA expressed in human bladder detrusor is $\beta 3-\mathrm{AR}$, and $1.5 \%$ and $1.4 \%$ of $\beta$-AR mRNA are $\beta 1-\mathrm{AR}$ and $\beta 2-\mathrm{AR}$ mRNAs, respectively. In that report, they demonstrated that $\beta 3$ AR mRNA was slightly, but not significantly, up-regulated in the obstructed bladder group. Masunaga et al. ${ }^{16}$ reported that in pig bladder, $\beta 3$-ARs mediate the inhibitory effect of agonists on detrusor contractions via the urothelium. Also Otsuka et al. who reported the presence of $\beta 1-, \beta 2$ - and $\beta 3$-ARs in human bladder urothelium ${ }^{17}$ suggested that $\beta$-AR agonists stimulated the release of an unidentified inhibitory factor from the urothelium that reduced detrusor contraction.

Based on these reports, we found it of interest toinvestigate the possible relationship between urodynamic findings and the mucosal levels of $\beta 3$-AR mRNA. Between the SC and LC groups, and between the DO+ and DO- groups, there were no significant differences in the expression of mucosal $\beta 3-\mathrm{AR}$ mRNA. In contrast, in the severe BOO group, the expression 
level of $\beta 3$-AR mRNA in the mucosa was significantly lower than that in the mild $\mathrm{BOO}$ group, suggesting that the expression of $\beta 3-\mathrm{AR}$ mRNA may be dependent on the degree of obstruction. Both the degree of obstruction and the bladder changes induced by obstruction may be time-dependent. In the animal studies of Park et al. and Barendrecht et al., mentioned previously, the expression of $\beta 3$-AR mRNA was studied at different time points after the induction of BOO., ${ }^{2,3}$ Barendrecht et al. studied their animals 7 days after the obstruction, whereas Park et al. made their analyses 8 weeks after BOO induction. No significant changes in the expression of $\beta 3$-AR mRNA were found at any of the time points, and this would not support the speculation that time-dependent bladder changes are of importance for the $\beta 3$-AR mRNA expression. However, in neither of these studies, the mucosa was analyzed separately from the detrusor muscle. This was done in the present study, showing a significantly lower $\beta 3$-AR mRNA expression in the severe BOO group. However, it is difficult to compare the results of obstruction in humans and in rats, and the clinical relevance of the present finding may be questioned, since it was not related to the occurrence of DO or symptom scores. On the other hand, mucosal $\beta 3$-ARs may be a target for therapeutically administered $\beta 3-\mathrm{AR}$ agonists. If the occurrence of $\beta 3-\mathrm{AR}$ mRNA corresponds to the presence of receptor protein, this could mean that severely obstructed men could be less responsive to such treatment than those with mild obstruction.

We are aware that our study has several limitations. The number of subjects is relatively small. Also, because of the limited amount of tissue contained in each biopsy, we did not perform Western blot analyses or 
immunohistochemistry for the presence of the $\beta 3$-AR proteins. Thus, our findings may or may not accurately reflect the level of the receptors themselves, which can be determined by post-translational regulation and the rate of receptor degradation. Further studies are required to confirm our findings and to quantify the amounts of $\beta 3$-ARs in both normal bladders and bladders from patients with BPO and LUTS to assess the clinical relevance, if any, of our observations. 


\section{CONCLUSIONS}

In BPO patients with LUTS, there was no relationship between the expression of urinary bladder mucosal $\beta 3$-AR mRNA and bladder capacity or the existence of DO measured during urodynamic study. On the other hand, $\beta 3$-AR mRNA in the bladder mucosa of patients with severe $\mathrm{BOO}(\geqq \mathrm{V})$ was significantly less than in patients with mild BOO $(\leqq I V)$. These results suggest that the presence of $\beta 3$-ARs might be affected by the degree of BOO. The exact function of $\beta 3$-ARs in the bladder urothelium awaits further investigation. 


\section{Disclosure}

None of the authors have any conflicting interests. This study was not supported by any federal or industrial resources. 


\section{REFERENCES}

1. Chapple C, Wyndaele JJ, Van Kerrebroeck P, Radziszewski P, Dvorak V, Boerrigter P. Dose-ranging study of once-daily mirabegron (YM178), a novel selective $\beta 3$-adrenoceptor agonist, in patients with overactive bladder (OAB). Eur Urol 2010; (Supple 9):249.

2. Park MG, Park HS, Lee JG, Kim HJ. Changes in awake cystometry and expression of bladder $\beta$-adorenoceptors after partial bladder outlet obstruction in male rats. Int Neurourol J 2010; 14:157-163.

3. Barendrecht MM, Frazier EP, Vrydag W, Alewijnse AE, Peters SLM, Michel MC. The effect of bladder outlet obstruction on $\alpha 1-$ and $\beta$ adrenoceptor expression and function. Neurourol Urodyn 2009; 28:349355.

4. Homma Y, Yoshida M, Seki N, Yokoyama O, Kakizaki H, Gotoh M, et al. Symptom assessment tool for overactive bladder syndrome - overactive bladder symptom score. Urology 2006; 68:318-323.

5. Abrams P, Cardozo L, Fall M, Griffiths D, Rosier P, Ulmsten U, et al. Standardisation Sub-committee of the International Continence Society. The standardization of terminology of lower urinary tract function: Report from the Standardization Sub-committee of the International Continence Society. Neurourol Urodyn 2002; 21:167-178. 
6. Wyndaele JJ. The normal pattern of perception of bladder filling during cystometry studied in 38 young healthy volunteers. J Urol 1998; 160:479481.

7. Wyndaele JJ, De Wachter S. Cystometrical sensory data from a normalpopulation: Comparison of two groups of young healthy volunteers examined with 5 years interval. Eur Urol 2002; 42:34-38.

8. Emorine LJ, Marullo S, Briend-Sutren MM, Patey G, Take K, DelavierKlutchko C, et al. Molecular characterization of the human beta 3adrenergic receptor. Science 1989; 245:1118-1121.

9. Igawa Y, Yamazaki Y, Takeda H, Hayakawa K, Akahane M, Ajisawa Y, et al. Functional and molecular biological evidence for a possible beta3adorenoceptor in the human detrusor muscle. Br J Pharmacol 1999; 126:819-825.

10. Takeda M, Obara K, Mizusawa T, Tomita Y, Arai K, Tsutsui T, et al. Evidence for beta3-adrenoceptor subtypes in relaxation of the human urinary bladder detrusor: analysis by molecular biological and pharmacological methods. J Pharmacol Exp Ther 1999; 288:1367-1373. 
11. Fujimura T, Tamura K, Tsutsumi T, Yamamoto T, Nakamura K, Koibuchi $\mathrm{Y}$, et al. Expression and possible functional role of the beta3-adrenoceptor in human and rat detrusor muscle. J Urol 1999; 161:680-685.

12. Andersson KE, Wein AJ. Pharmacology of the lower urinary tract: basis for current and future treatments of urinary incontinence. Pharmacol Rev 2004; 56:581-631.

13. Yamaguchi O, Chapple CR. Beta3-adrenoceptors in urinary bladder. Neurourol Urodyn 2007; 26:752-756.

14. Andersson KE, Gratzke C. Pharmacology of alpha 1-adrenoceptor antagonists in the lower urinary tract and central nervous system. Nat Clin Pract Urol 2007; 4:368-378.

15. Nomiya M, Yamaguchi O. A quantitative analysis of mRNA expression of alpha 1 and beta-adrenoceptor subtypes and their functional roles in human normal and obstructed bladders. J Urol 2003; 170:649-653.

16. Masunaga K, Chapple CR, McKay NG, Yoshida M, Sellers DJ. The $\beta 3$ adrenoceptor mediates the inhibitory effects of $\beta$-adrenoceptor agonists via the urothelium in pig bladder dome. Neurourol Urodyn 2010; 29:13201325 
17. Otsuka A, Shinbo H, Matsumoto R, Kurita Y, Ozono S. Expression and functonal role of beta-adrenoceptors in the human urinary bladder urothelium. Naunyn Schmiedebergs Arch Pharmacol. 2008; 377:473-481. 


\section{Figure Caption}

Figure 1. Expression level of $\beta 3$-AR mRNA. There were no significant differences in $\beta 3$-AR mRNA expression between bladders of the Small Capacity and Large Capacity groups (A) or between the DO+ and DO- groups (B). However expression was significantly less in patients with severe BOO $(\leqq \mathrm{IV})$ group compared to the patients with mild $\mathrm{BOO}(\leqq \mathrm{IV})$ group $(\mathrm{C})(\mathrm{p}=$ $0.043)$. 